There are many professionals who do sterling work. I respect persistent prosecutors, prudent police personnel, and sterling social workers. I am sorry to say that the lack of training and of specialist clinics at academic hospitals may well play a role in many cases of dodging doctors, dodging of examining children, and dodging court witnesses.

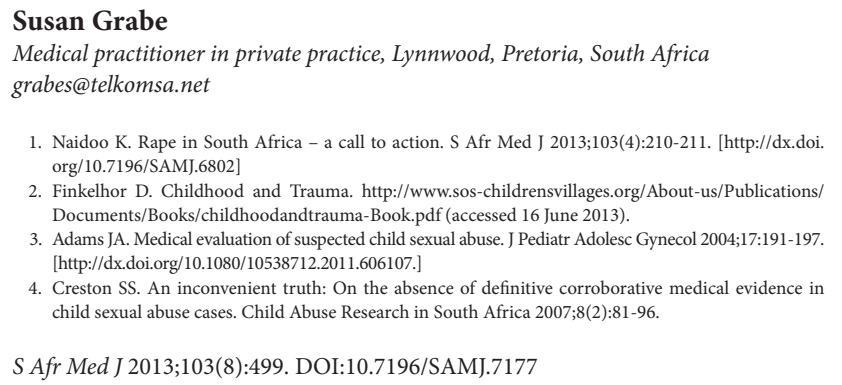

\title{
Child sexual abuse exacerbated by inadequate services
}

To the Editor: The editorial entitled 'Rape in South Africa - a call to action $^{\text {[1] }}$ implores me to respond. The author aptly describes the landscape of sexual violence as it intersects with medicine and the limitations in the response. Child sexual abuse (CSA) is included in this lament, and on this I wish to cast some more light. The inherent nature of CSA includes secrecy, serious threats, perpetrators who are part of the extended family, victims who are often preschool children, and a host of other factors that complicate management. The grooming process and access that perpetrators have to children precludes immediate alarm. It is clear that children need specialised services, including psychological, social, medical and legal services, necessitating a multi-professional approach. Currently, these are seldom available outside the private sector, and are often subcontracted by NGOs to protect children. Successful prosecution is also seldom possible.

As described by Dr Naidoo, the absence of services is apparent for rape victims, but even more so for CSA victims. Finkelhor ${ }^{[2]}$ reports that community epidemiological surveys confirm a prevalence of $20 \%$ of CSA. CSA is no small problem, just as is rape. My concern is the lack of training and exposure to services on a pre- and postgraduate level at medical schools. An effective clinical medico-legal system will need to be staffed by trained professionals. It should be appreciated that work in this field is emotionally demanding and needs pertinent expertise, support and guidance, without which little success can be achieved. Doctors need to be taught how to conduct a proper examination, interpret the findings, and be proficient in the techniques of managing expert witnesses during court procedures - the foregoing all based on international research in this field. ${ }^{[3]}$ Although medical evidence is often sought to confirm sexual abuse, the correct interpretation of findings is crucial; contrary to popular belief, this confirmation is seldom possible from a medical evaluation. ${ }^{[4]}$ 